\title{
PEDICULOSIS CAPITIS: PREVALENCE AND ITS ASSOCIATED FACTORS IN PRIMARY SCHOOL CHILDREN LIVING IN RURAL AND URBAN AREAS IN KAYSERI, TURKEY
}

\author{
Mustafa Gulgun ${ }^{1}$, Elçin Balcı', Abdülbaki Karaoğlu', Oğuzhan Babacan ${ }^{1}$, Türker Türker ${ }^{3}$ \\ ${ }^{1}$ Department of Pediatrics, Gülhane Military Medical Faculty, Ankara, Turkey \\ ${ }^{2}$ Department of Public Health, Erciyes University, Kayseri, Turkey \\ ${ }^{3}$ Department of Public Health, Gülhane Military Medical Faculty, Ankara, Turkey
}

\section{SUMMARY}

Objective: The aim of this study was to investigate the prevalence and risk factors of pediculosis capitis in schoolchildren living in rural and urban areas in Kayseri, a city located in central Anatolia in Turkey.

Methods: This cross-sectional school-based study was performed in 24 randomly selected public schools. A total of 8,122 schoolchildren aged $5-16$ years, from kindergarten to eighth grade, were examined for the presence of pediculosis capitis. A child was defined as being infested by the presence of live or dead lice or eggs/nits. The results were analyzed using the chi-squared test and logistic regression analysis.

Results: The overall prevalence of head lice infestation was $13.1 \%$. Pediculosis was more frequent in girls $(25.2 \%)$ than in boys $(0.86 \%)(p<0.001)$. The prevalence was lower in children aged $5-8$ years than in those aged 9-11 or $12-16$ years $(p<0.001)$. In multiple regression analyses, the variables demonstrating statistically significant association with pediculosis were: being a girl ( $\mathrm{OR}=40.93 ; 95 \% \mathrm{Cl}=29.06-57.66)$, being $9-11$ years old $(\mathrm{OR}=1.54 ; 95 \% \mathrm{Cl}=1.25-1.89$ ), residing with $\geq 3$ siblings ( $\mathrm{OR}=1.98 ; 95 \% \mathrm{Cl}=1.57-2.50)$, having a mother with no education (OR=1.73; $95 \%$ $\mathrm{Cl}=1.29-2.33)$, having a father with no education $(\mathrm{OR}=1.45 ; 95 \% \mathrm{Cl}=1.08-1.94)$, living in a rural area $(\mathrm{OR}=2.34 ; 95 \% \mathrm{Cl}=2.02-2.71)$ and living in a one-room house (OR=2.39; $95 \% \mathrm{Cl}=1.41-4.08)$.

Conclusions: Pediculosis capitis remains a health problem in schoolchildren in Kayseri, Turkey. In addition to improvement in socioeconomic status, collaborative and participation efforts among physicians, nurses, teachers, and parents are necessary to maintain effective epidemiological surveillance and provide treatment.

Key words: pediculosis capitis, prevalence, schoolchildren, Turkey

Address for correspondence: M. Gulgun, Department of Pediatrics, Gülhane Military Medical Faculty, Ankara, Turkey. E-mail: mustafagulgun@ yahoo.com

\section{INTRODUCTION}

The human head louse, Pediculus humanus capitis, is a common public health concern, especially in children. It is an obligate holometabolous ectoparasite that spends its complete life cycle in hair on a human head (1). Transmission occurs mainly by direct person-to-person contact or by instruments such as shared combs, pillows and hats. Climate, geography, ethnicity, and hygienic conditions play a role in spreading lice. Head lice are bloodsucking insects that can cause pruritus, excoriation, conjunctivitis, secondary bacterial infection, local post-therapeutic dermatitis, posterior neck adenopathy, unspecific generalized dermatitis, anaemia, and allergic reactions resulting in nasal obstruction and rhinorrhea. Head lice infestation may also lead to psychological distress and may disrupt learning performance in schoolchildren (1-5). In addition, the likelihood of outbreaks of pediculosis in schoolchildren is another concern (6). Therefore, it is essential to obtain epidemiological data from different regions to enable strategic planning for the control and prevention of pediculosis.

Pediculosis capitis is more prevalent in schoolchildren and the rate of head lice infestation shows a wide range (up to $80 \%$ ) among various countries worldwide (5). This study aimed to determine the prevalence and risk factors of pediculosis capitis in schoolchildren living in urban and rural areas of Kayseri, Turkey.

\section{MATERIALS AND METHODS}

This cross-sectional school-based epidemiological study was conducted in schoolchildren in Kayseri. Kayseri, a city with a total of 139,422 schoolchildren, is located in central Anatolia, which is a geographic and historical term defining the westernmost protrusion of Asia that forms the majority of the Republic of Turkey (Fig. 1). The climate in Kayseri is cold, snowy and wet in winter, but dry and hot in summer. Permission to conduct the study was obtained from the Governorship of Kayseri. This study was approved by the Erciyes University Ethics Committee in Kayseri. Children from 20 schools with kindergarten and four schools without kindergarten (15 urban and 9 rural schools) were evaluated. In Turkey, kindergarten is the first year of education in a primary or elementary school, similar to that in the US. Although not compulsory, parents usually enroll their children 


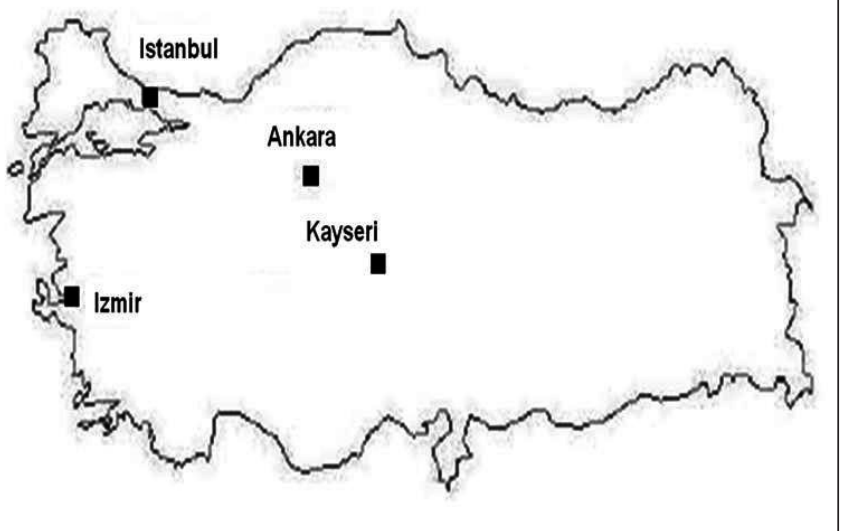

Fig. 1. The location of Kayseri in Turkey.

in kindergarten at five or six years of age by September 1 of the current school year. Using a simple randomized sampling method, a total of 8,122 schoolchildren from kindergarten to eighth grade (4,032 boys $-49.6 \%$; and 4,090 girls $-50.4 \%$ ), aged 5-16 years were examined for the presence of pediculosis capitis in 24 primary public schools located in rural and urban areas of Kayseri; 5,479 (67.5\%) children from the center of Kayseri and 2,643 (32.5\%) from rural districts of Kayseri. Each student was examined once for pediculosis by a physician. Hair, neck and areas behind the ears were examined for head lice and/or eggs/nits by full head visual examination using a magnifying lens and fine-toothed comb, if necessary, by separating hair every $3 \mathrm{~cm}$ in sufficient daylight for about 5 minutes. A child was defined as being infested by the presence of live or dead lice or eggs/nits (5). The number and position of nits in the scalp, presence of any trophic stages, hair features, and intensity of infestation were not recorded.

Children, teachers and parents were asked to complete a questionnaire to evaluate the influence of risk factors on the prevalence of pediculosis. We collected information regarding the sex and age of the child as well as socioeconomic factors including parents' educational status and occupational characteristics, number of siblings in the home, family income per month (in USD), frequency of bathing, use of cleansing material for hair washing, number of rooms in the house, and residing in an urban versus rural area.

Statistical analysis was conducted using the SPSS software package, version 15.0 (Chicago, IL). Categorical variables were defined as the number and percentage (\%) and analyzed using the chi-square test. Multivariable logistic regression (LR) analysis was performed on variables having a significant effect on lice infestation using the Backward LR method. P values less than 0.05 were accepted to indicate statistical significance.

\section{RESULTS}

Head lice infestation was detected in $25.2 \%(1,031 / 4,090)$ of girls and $0.86 \%(35 / 4,032)$ of boys. This difference between boys and girls was statistically significant $(\mathrm{p}<0.05)$. The prevalence of pediculosis was the lowest in children attending kindergarten $(3.5 \%)$ and the highest in children attending eighth grade (17.8\%). The infestation rate was significantly lower in the kindergarten, first and second grade group ( $\mathrm{p}<0.05)$. The infestation rate in the 5-8 year-old group was lower than in the age groups from 9-11 and $12-16$ years $(p<0.05)$. Infestation was diagnosed in $9.7 \%$ of children in urban schools and $20 \%$ of children in rural schools $(p<0.05)$. The prevalence of head lice infestation was higher in children with a lower family income, living in a house with one room, having parents with a low educational level, and living with three or more siblings $(\mathrm{p}<0.05)$. The prevalence was $5.7 \%$ in children of employed mothers and $13.3 \%$ in children of housewives $(p<0.05)$. The prevalence of pediculosis capitis did not differ significantly with respect to fathers' occupation, frequency of bathing, and use of cleansing material for hair washing $(p>0.05)$. Overall, the prevalence of head lice infestation in 20 schools with kindergarten was not significantly different from that measured in four schools with no kindergarten. The socio-demographic characteristics and the prevalence of pediculosis capitis in this study population are shown in Table 1.

According to our multiple logistic regression analysis results, the variables demonstrating statistically significant associations with pediculosis capitis were sex, age, number of siblings, mother's and father's educational levels, the number of rooms in the home, and residence in a rural versus urban setting (Table 2). Pediculosis capitis in girls was found approximately 41 -fold more frequently than in boys. Living in a rural district and being in the age groups of 9-11 and 12-16 years was associated with 2.3- and 1.5-fold greater risk of pediculosis capitis, respectively.

\section{DISCUSSION}

Pediculosis capitis has been documented since ancient times, and remains a common ectoparasite worldwide. Infestation rates differ according to geography, season, examination technique, reporting of active infestation or presence of nits, and potential introduction of effective pediculicides (7-9). This study reported the overall prevalence of $13.1 \%$ in the city of Kayseri, Turkey. Epidemiological studies performed in primary schoolchildren found that the prevalence of pediculosis capitis was $28.8 \%$ in England, $1.59 \%$ in Poland, $8.9 \%$ in Belgium, 15\% in France, 9.39\% in Spain, $78.6 \%$ in Libya, $55 \%$ in Israel, $8 \%$ in Lebanon, $26.6 \%$ in Jordan, $6.85 \%$ in Iran, $16.59 \%$ in India, $40 \%$ in Taiwan, $4.1 \%$ in Korea, $33.7 \%$ in Australia, $42.7 \%$ in Brazil, and 29.7\% in Argentina (1, 4, 5, 7, 10-15). The prevalence of head lice in Turkey varied geographically: $9.5 \%$ in Eastern Turkey, $2.2 \%$ in Western Turkey, 6.8\% in Southern Turkey, and 5.4\% in Northern Turkey. In Turkey, the highest reported prevalence of pediculosis was $50.8 \%$ in girls and $9.8 \%$ in boys $(4,16-20)$. Two studies of pediculosis capitis screening in our region have been published. The first reported that the prevalence of infestation was $20.4 \%$ in girls and 2\% in boys (21). The second reported an infestation rate of $16.4 \%$ in girls and $2.1 \%$ in boys (3). Compared to previous reports, we detected a slightly higher prevalence of pediculosis capitis in our region. This higher prevalence might be attributed to the fact that our study population consisted of children attending schools in both urban and rural areas, whereas study populations from urban or rural districts in previous reports were evaluated separately.

In this study, the prevalence of infestation in girls was about 41-fold higher than in boys. Because head-to-head contact is as 
Table 1. Socio-demographic features of the study subjects and the prevalence of pediculosis capitis

\begin{tabular}{|c|c|c|c|c|c|}
\hline \multirow{2}{*}{ Features } & & \multirow{2}{*}{$\begin{array}{c}\text { Total } \\
\mathrm{n}\end{array}$} & \multicolumn{2}{|c|}{ Pediculosis capitis frequency } & \multirow{2}{*}{$\mathrm{p}$} \\
\hline & & & $n$ & $\%$ & \\
\hline \multirow{2}{*}{ Sex } & Boys & 4,032 & 35 & 0.86 & \multirow{2}{*}{$<0.00$} \\
\hline & Girls & 4,090 & 1,031 & 25.2 & \\
\hline \multirow{3}{*}{ Age (year) } & $5-8$ & 1,889 & 177 & 9.3 & \multirow{3}{*}{$<0.00$} \\
\hline & $9-11$ & 3,325 & 444 & 13.3 & \\
\hline & $12+$ & 2,908 & 445 & 15.3 & \\
\hline \multirow{3}{*}{ Grade } & Kindergarten-2 & 2,336 & 240 & 10.2 & \multirow{3}{*}{$<0.00$} \\
\hline & $3-5$ & 3,018 & 411 & 13.6 & \\
\hline & $6-8$ & 2,768 & 415 & 14.9 & \\
\hline \multirow{3}{*}{ Number of siblings } & $1-2$ & 2,376 & 173 & 7.2 & \multirow{3}{*}{$<0.00$} \\
\hline & $3-4$ & 4,291 & 598 & 13.9 & \\
\hline & $5+$ & 1,455 & 295 & 20.2 & \\
\hline \multirow{3}{*}{$\begin{array}{l}\text { Mother's education } \\
\text { level }\end{array}$} & No education & 1,534 & 268 & 17.4 & \multirow{3}{*}{$<0.00$} \\
\hline & Elementary & 5,403 & 703 & 13.0 & \\
\hline & > Elementary & 1,185 & 95 & 8.0 & \\
\hline \multirow{3}{*}{ Father's education level } & No education & 1,565 & 230 & 14.6 & \multirow{3}{*}{$<0.00$} \\
\hline & Elementary & 5,312 & 740 & 13.9 & \\
\hline & > Elementary & 1,245 & 96 & 7.7 & \\
\hline \multirow{2}{*}{ Mother's occupation } & Housewife & 7,915 & 1,054 & 13.3 & \multirow{2}{*}{0.02} \\
\hline & Employed & 207 & 12 & 5.7 & \\
\hline \multirow{2}{*}{ Father's occupation } & Unemployed & 2,059 & 342 & 16.6 & \multirow{2}{*}{$<0.001$} \\
\hline & Employed & 6,063 & 724 & 11.9 & \\
\hline \multirow{3}{*}{$\begin{array}{l}\text { Family income (per } \\
\text { month for each family, } \\
\text { in US dollars) }\end{array}$} & Poor $(<\$ 300)$ & 2,060 & 342 & 16.6 & \multirow{3}{*}{$<0.00$} \\
\hline & Good $(\$ 300-600)$ & 5,437 & 672 & 12.3 & \\
\hline & Fine $(>\$ 600)$ & 625 & 52 & 8.3 & \\
\hline \multirow{3}{*}{$\begin{array}{l}\text { Cleansing material for } \\
\text { hair washing }\end{array}$} & Soap & 1,354 & 159 & 11.7 & \multirow{3}{*}{0.54} \\
\hline & Shampoo & 4,104 & 574 & 13.9 & \\
\hline & Soap and shampoo & 2,664 & 333 & 12.5 & \\
\hline \multirow{2}{*}{ Bathing per week } & More than once & 4,342 & 601 & 13.8 & \multirow{2}{*}{0.40} \\
\hline & Once or less & 3,780 & 465 & 12.3 & \\
\hline \multirow{2}{*}{$\begin{array}{l}\text { Kindergarten included } \\
\text { in school }\end{array}$} & Yes & 6,789 & 882 & 12.9 & 012 \\
\hline & No & 1,333 & 184 & 13.8 & 0.42 \\
\hline Urban versus rural & Urban & 5,479 & 536 & 9.7 & $<0001$ \\
\hline living area & Rural & 2,643 & 530 & 20.0 & -0.001 \\
\hline & 1 & 116 & 27 & 23.2 & \\
\hline Number of rooms & 2 & 979 & 174 & 17.7 & $<0.001$ \\
\hline & $3+$ & 7,027 & 865 & 12.3 & \\
\hline
\end{tabular}

important as passive transmission of pediculosis with shared objects like barrettes, combs and towels (3), this difference might be explained by differing behavioural characteristics, such as closer contact between girls than between boys. There are conflicting reports in the literature about the relationship between higher pediculosis rates and long hair in girls $(2,22)$. The predominance of long-haired girls may provide a reservoir for the survival and reproduction of lice. Unfortunately, we did not evaluate the influence of hair length on head lice prevalence. Skin factors or effects of hormones such as progesterone and prolactin may be associated with this tendency $(1,7,10,11,15)$. Low prevalence in boys could be explained by the hypothesis that short hair of boys impedes detection of an infestation $(5,9)$.

Children in the age group 6-12 years are at the highest risk for pediculosis capitis (12). A study from Jordan reported a higher infestation rate in younger children $(<9$ years) $(5)$, whereas a survey from Greece showed that risk increased by $15 \%$ for every year of age (9). In accordance with Soultana et al. (9), in our study we found an increased prevalence of head lice with increasing age. This may be due to the greater role of parents in taking care 
Table 2. Multivariable logistic regression analysis of the relationship between pediculosis capitis infestation and potential risk factors. Variables with insignificant multivariate OR values are not shown in Table 2.

\begin{tabular}{|c|c|c|c|c|}
\hline Parameters (reference) & & $p$ value & OR & $95 \% \mathrm{Cl}$ \\
\hline \multirow{2}{*}{ Sex } & Boy & & 1 & \\
\hline & Girl & $<0.001$ & 40.93 & $29.06-57.66$ \\
\hline \multirow{3}{*}{ Age } & $5-8$ & & 1 & \\
\hline & $9-11$ & $<0.001$ & 1.54 & $1.25-1.89$ \\
\hline & $12-16$ & $<0.001$ & 1.54 & $1.25-1.90$ \\
\hline \multirow{3}{*}{ Number of siblings } & $1-2$ & & 1 & \\
\hline & $3-4$ & $<0.001$ & 1.55 & $1.27-1.88$ \\
\hline & $5+$ & $<0.001$ & 1.98 & $1.57-2.50$ \\
\hline \multirow{3}{*}{ Mother's education } & > Elementary & & 1 & \\
\hline & Elementary & 0.073 & 1.26 & $0.98-1.62$ \\
\hline & No education & $<0.001$ & 1.73 & $1.29-2.33$ \\
\hline \multirow{3}{*}{ Father's education } & > Elementary & & 1 & \\
\hline & Elementary & 0.002 & 1.48 & $1.15-1.89$ \\
\hline & No education & 0.015 & 1.45 & $1.08-1.94$ \\
\hline \multirow{2}{*}{ Urban vs. rural living area } & Urban & & 1 & \\
\hline & Rural & $<0.001$ & 2.34 & $2.02-2.71$ \\
\hline \multirow{3}{*}{ Number of rooms } & $3+$ & & 1 & \\
\hline & 2 & $<0.001$ & 1.50 & $1.23-1.84$ \\
\hline & 1 & 0.001 & 2.39 & $1.41-4.08$ \\
\hline
\end{tabular}

of small children. Additionally, being independent from parents care, participating in closer relationships and more social activities with friends, and the lack of information about pediculosis transmission routes may facilitate infestation of older children.

In this study, low educational levels of parents, low family income, high number of siblings, low number of rooms in the house, and living in a rural district indicated low socioeconomic status. However, head lice infestation occurs in all socioeconomic classes. Studies from Poland, Belgium, and Jordan proposed that improvement in family income and health conditions lowered the prevalence of pediculosis $(5,13,14)$. Statistically significant associations between parents' educational level, family income, residential status, and prevalence rate were demonstrated in a village in Turkey (23). One survey found an increased pediculosis prevalence in children of mothers with low educational levels (24). A report from Istanbul, Turkey, showed 20\% prevalence in schoolchildren educated in a district in which most houses were in a slum with poorly developed infrastructure compared with $10.48 \%$ in children who were educated in a well-developed district (25). Similar to previous reports, our study demonstrated an inversely proportional relationship between head lice prevalence and socioeconomic conditions.

Our results showing an increased pediculosis prevalence in children with more siblings and low residential status - findings confirmed by the previous reports $(23,24)$. Having more siblings may cause higher infestation rates because parents have less time per a child to perform laundry and personal cleansing. Overcrowding facilitates transmission of pediculosis due to closer contact with siblings in fewer rooms in the house.

Although the pediculosis rate was higher in families of low socioeconomic status, which is closely related to poor hygiene, the link between poor hygiene of the host and pediculosis is controversial. Better hygiene has been defined as an important component for prevention of pediculosis. A study from Jordan determined a significant association between more frequent hair washing and lower rate of infestation (5). Similarly, a higher pediculosis rate was detected in schoolchildren with a low frequency of bathing (4). On the other hand, another study detected no statistically significant association between head lice infestation and frequency of bathing (7). Some authors have claimed that personal hygiene is important, whereas others have not emphasized the importance of personal cleanliness in pediculosis capitis $(5,7,26)$. We did not detect any significant associations among infestation rates and frequency of bathing and use of a cleansing material for hair washing.

Pediculosis was defined as an urban problem in Nigeria (27). However, higher rates of head lice infestation were detected in rural schools in Poland (13) as well as in our study. The lower prevalence in children living in urban areas is probably due to higher living standards. Climate conditions in Kayseri may be another reason. Winter is cold, snowy and icy in Kayseri and the accessibility of urban areas in this period for those living in rural areas is difficult. This may influence access to medical facilities that would allow timely treatment of infested children in urban areas compared to those in rural areas.

Many people in society consider pediculosis capitis as an uncomfortable condition rather than a clinical disease. Moreover, many families do not know how to recognize head lice infestation. Parents may not be aware of active pediculosis capitis infestation in $10 \%$ of girls and $23.3 \%$ of boys (11). This lack of awareness regarding the seriousness of pediculosis and the resistance to use of pediculosis capitis drugs has perpetuated this condition in school-aged children. Large-scale information campaigns and 
more health screening programmes designed to reach the majority of children and families are necessary for effective control of pediculosis. Collaborative efforts among health staff, physicians, nurses, teachers, and parents are necessary to maintain effective epidemiological surveillance and provide the optimal treatment.

\section{Conflict of Interest}

None declared

\section{REFERENCES}

1. Gutiérrez MM, González JW, Stefanazzi N, Serralunga G, Yañez L, Ferrero AA. Prevalence of Pediculus humanus capitis infestation among kindergarten children in Bahía Blanca city, Argentina. Parasitol Res. 2012 Sep;111(3):1309-13.

2. Catalá S, Junco L, Vaporaky R. Pediculus capitis infestation according to sex and social factors in Argentina. Rev Saude Publica. 2005 Jun;39(3):438-43.

3. Oğuzkaya Artan M, Baykan Z, Koç AN. The prevalence of Pediculus capitis in students of eight primary schools in the rural area of the Kayseri province. Turkiye Parazitol Derg. 2006;30(2):112-4. (In Turkish.)

4. Dursun N, Cengiz ZT. Distribution of head lice in the Ercis district of Van. Turkiye Parazitol Derg. 2010;34(1):45-9. (In Turkish.)

5. Mohammed AL. Head lice infestation in schoolchildren and related factors in Mafraq governorate, Jordan. Int J Dermatol. 2012 Feb;51(2):16872.

6. Rupeš V, Moravec J, Chmela J, Ledvinka J, Zelenková J. A resistance of head lice (Pediculus capitis) to permethrin in Czech Republic. Cent Eur J Public Health. 1995 Feb;3(1):30-2.

7. Kokturk A, Baz K, Bugdayci R, Sasmaz T, Tursen U, Kaya TI, et al. The prevalence of pediculosis capitis in schoolchildren in Mersin, Turkey. Int J Dermatol. 2003 Sep;42(9):694-8.

8. Falagas ME, Matthaiou DK, Rafailidis PI, Panos G, Pappas G. Worldwide prevalence of head lice. Emerg Infect Dis. 2008 Sep;14(9):1493-4.

9. Soultana V, Euthumia P, Antonios M, Angeliki RS. Prevalence of pediculosis capitis among schoolchildren in Greece and risk factors: a questionnaire survey. Pediatr Dermatol. 2009 Nov-Dec;26(6):701-5.

10. Oh JM, Lee IY, Lee WJ, Seo M, Park SA, Lee SH, et al. Prevalence of pediculosis capitis among Korean children. Parasitol Res. 2010 Nov;107(6):1415-9.

11. Speare R, Buettner PG. Head lice in pupils of a primary school in Australia and implications for control. Int J Dermatol. 1999 Apr;38(4):285-90.

12. Khokhar A. A study of pediculosis capitis among primary school children in Delhi. Indian J Med Sci. 2002 Sep;56(9):449-52.

13. Buczek A, Markowska-Gosik D, Widomska D, Kawa IM. Pediculosis capitis among schoolchildren in urban and rural areas of eastern Poland. Eur J Epidemiol. 2004;19(5):491-5.
14. Willems S, Lapeere H, Haedens N, Pasteels I, Naeyaert JM, De Maeseneer $\mathrm{J}$. The importance of socio-economic status and individual characteristics on the prevalence of head lice in schoolchildren. Eur J Dermatol. 2005 Sep-Oct;15(5):387-92.

15. Toloza A, Vassena C, Gallardo A, González-Audino P, Picollo MI. Epidemiology of Pediculosis capitis in elementary schools of Buenos Aires, Argentina. Parasitol Res. 2009 Jun;104(6):1295-8.

16. Çetinkaya Ü, Hamamcı B, Delice S, Ercal BD, Gücüyetmez S, Yazar $\mathrm{S}$, et al. The prevalence of Pediculus humanus capitis in two primary schools of Hacilar, Kayseri. Turkiye Parazitol Derg. 2011;35(3):151-3. (In Turkish.)

17. Akisu C, Aksoy U, Delibas SB, Ozkoc S, Sahin S. The prevalence of head lice infestation in school children in Izmir, Turkey. Pediatr Dermatol. 2005 Jul-Aug;22(4):372-3.

18. Inanir I, Sahin MT, Gündüz K, Dinç G, Türel A, Oztürkcan S. Prevalence of skin conditions in primary school children in Turkey: differences based on socioeconomic factors. Pediatr Dermatol. 2002 Jul-Aug;19(4):307-11.

19. Ozçelik S, Değerli S, Aslan A. Investigation of the prevalence of Pediculus in Alahaci village primary school students in the Sivas province. Turkiye Parazitol Derg. 2006;30(3):184-6. (In Turkish.)

20. Yilmaz M, Korkmaz E, Karakoç S, Yaztürk S, Kizirgil A, Yakupoğullari Y. Investigation of intestinal parasites and ectoparasites in three primary school students in Elaziğ. Turkiye Parazitol Derg. 2007;31(2):139-41. (In Turkish.)

21. Kisioglu AN, Gokmerdan A. Investigation of Pediculus humanus capitis in the students of Ayse Baldoktu apprentice education school in Kayseri. Turkiye Parazitol Derg. 1995;19(4):531-4. (In Turkish.)

22. Counahan M, Andrews R, Büttner P, Byrnes G, Speare R. Head lice prevalence in primary schools in Victoria, Australia. J Paediatr Child Health. 2004 Nov;40(11):616-9.

23. Yazar S, Sular C, Sevgi I, Akgunduz N, Cinar MC, Kitapcioglu G, et al. Investigation of the prevalence of Pediculus humanus capitis in the schools of Kemalpasa. Turkiye Parazitol Derg. 1999;23(3):273-8. (In Turkish.)

24. Akisu Ç, Sari B, Aksoy U, Özkoç S, Öztürk S. Investigation of the prevalence of pediculus capitis in a primary school in Narlidere and comparison of these results with the study in the same school carried out previously. Turkiye Parazitol Derg. 2003;27(1):45-8. (In Turkish.)

25. Yücel A, Çalışır B, Polat E, Aslan M, Ünver AC. A research on the spread of head louse (Pediculus humanus) among the pupils of primary schools in six different towns of Istanbul. Turkiye Parazitol Derg. 1994;18(4):492-7. (In Turkish.)

26. Mahmud S, Pappas G, Hadden WC. Prevalence of head lice and hygiene practices among women over twelve years of age in Sindh, Balochistan, and North West Frontier Province: National Health Survey of Pakistan, 1990-1994. Parasit Vectors. 2011 Feb 2;4:11.

27. Ogunrinade AF, Oyejide CO. Pediculosis capitis among rural and urban schoolchildren in Nigeria. Trans R Soc Trop Med Hyg. 1984;78(5):590-2. 